\title{
Role of MMP-2 in Alveolar Epithelial Cell Repair after Bleomycin Administration in Rabbits
}

\author{
Shinobu Kunugi, Yuh Fukuda, Masamichi Ishizaki, and Nobuaki Yamanaka \\ Department of Pathology (SK, YF, MI, NY), and Fourth Department of Internal Medicine (SK), Nippon Medical \\ School, Tokyo, Japan
}

\begin{abstract}
SUMMARY: Matrix metalloproteinases (MMPs) have been implicated in the pathological processes of interstitial lung diseases. However, underlying mechanisms, particularly for activity levels and distribution of activated MMP-2 in the disease process, are yet to be elucidated. The present study investigated the immunolocalization of MMP-2, membrane type 1-matrix metalloproteinase (MT1-MMP), tissue inhibitor of metalloproteinase (TIMP)-2, p53, and Ki-67 in a rabbit model of bleomycin-induced pulmonary fibrosis. Gelatin zymography and in situ zymography were used to examine the activity and the localization of MMP-2. Furthermore, we performed Western blot and in situ hybridization for MT1-MMP, an activator for MMP-2. The total MMP-2 level estimated by gelatin zymography increased significantly at 3, 7, and 14 days after bleomycin administration, compared with controls. In the immunohistochemical study, immunoreaction for MMP-2 was strongest in alveolar epithelial cells among the cell populations. Swollen and/or elongated type II alveolar epithelial cells showed strong immunoreactions for MMP-2, MT1-MMP, and TIMP-2. After bleomycin administration, immunoreaction for p53 was observed in bronchiolar and alveolar epithelial cells. The proportion of p53-positive cells was high in epithelial cells from 1 to 14 days as MMP-2 levels were increased, suggesting that p53 may be responsible, at least in part, for the increase of MMP-2. The ratio of activated MMP-2 to total MMP-2 estimated by gelatin zymography increased significantly at $3,7,14$, and 28 days after bleomycin treatment. In situ zymography revealed that type II alveolar epithelial cells degraded gelatin. An increased expression of MT1-MMP protein was observed by Western blot following administration of bleomycin. In situ hybridization demonstrated that type II alveolar epithelial cells gave intense signal for MT1-MMP mRNA. These results suggest that type II alveolar epithelial cells express MT1-MMP and activate MMP-2 on their cell surfaces, which may lead to the elongation and migration of alveolar epithelial cells in the repair process of bleomycininduced pulmonary fibrosis. (Lab Invest 2001, 81:1309-1318).
\end{abstract}

$P$ ulmonary fibrosis and alveolar structural remodeling in interstitial lung diseases are associated with the production, deposition, and remodeling of the extracellular matrix. Extracellular proteases, particularly those belonging to the serine protease and matrix metalloproteinase (MMP) family, are involved in the pathophysiological processes of interstitial lung diseases (O'Connor and FitzGerald, 1994). MMPs are secreted in an inactive proenzyme form and then activated by proteolytic degradation. The activities of MMPs are inhibited by endogenous tissue inhibitor of metalloproteinases (TIMPs). MMP-2 degrades several components of basement membrane, including type IV collagen and laminin (Woessner, 1991). Expression of MMP-2 increases in bronchial, alveolar epithelial cells, macrophages, and fibroblasts in interstitial pneumonia (Fukuda et al, 1998; Hayashi et al, 1996). MMP-2 mRNA levels were up-regulated in a murine model of bleomycin-induced pulmonary fibrosis (Swiderski et al, 1998). Previously, we found in a rabbit model that

\section{Received June 25, 2001.}

This work was supported in part by a grant from The Promotion and Mutual Aid Corporation for Private Schools of Japan for the promotion of the advancement of education and research in graduate schools (SK). Address reprint requests to: Dr. Shinobu Kunugi, Department of Pathology, Nippon Medical School, 1-1-5 Sendagi, Bunkyo-ku, Tokyo, 113-8602, Japan. E-mail: ShinobuHemmi/Patho1@nms.ac.jp
MMP-2 was localized in the regenerating alveolar epithelial cells and that the active form of MMP-2 was detected in lung homogenates, suggesting that MMP-2 contributes to the reconstruction of alveoli in pulmonary fibrosis (Yaguchi et al, 1998). Furthermore, we observed the localization of MMP-2 in alveolar epithelial cells and the activation of MMP-2 in fetal rabbit lung, indicating an important role of MMP-2 in the formation of alveoli (Fukuda et al, 2000).

MMP-2 is activated by membrane-type (MT) MMPs, that is, cell surface activators in vivo (Sato et al, 1994). To date, six distinct MT-MMPs have been identified (Velasco et al, 2000). MT1-MMP was first identified as a cell membrane receptor and activator for MMP-2 (Sato et al, 1994). Formation of the trimolecular complex of the latent MMP-2, TIMP-2, and MT1-MMP is important for cell-mediated MMP-2 activation (Seiki, 1999).

MMP-2 is a downstream p53 target gene (Bian and Sun, 1997). p53 binds to the promotor region of the MMP-2 gene and regulates its gene expression. Exposure to bleomycin induces the cellular production of p53 protein (Kastan et al, 1991; Nelson and Kastan, 1994). p53 was detected in hyperplastic bronchial and alveolar epithelial cells of patients with idiopathic pulmonary fibrosis (Kuwano et al, 1996) and also in bleomycin-induced lung injury in mice (Kuwano et al, 2000; Mishra et al, 2000; Okudela et al, 1999). 
These several lines of evidence indicate the possible involvement of MMP-2 activated by MT1-MMP in the pathological process of bleomycin-induced pulmonary fibrosis. The present study investigated the localization of MMP-2, MT1-MMP, TIMP-2, p53, and Ki-67 in a rabbit model of bleomycin-induced pulmonary fibrosis, using immunostaining methods. We analyzed the MMP-2 activity (ie, gelatinolytic activity) in the lungs by gelatin zymography and in situ zymography. Furthermore, to see the expression and distribution of MT1-MMP in relation to the activation of MMP-2, Western blot for MT1-MMP protein and in situ hybridization for its mRNA were performed.

\section{Results}

\section{Histology and Immunohistochemistry}

Control Animals. By light microscopy, control rabbits showed normal alveolar structures (Fig. 1A). Mild edema of interstitial connective tissue and infiltration of inflammatory cells were observed as transient findings early after instillation of normal saline. Immunoreactions for MMP-2, MT1-MMP, and TIMP-2 were weakly recognized in bronchiolar cuboidal cells and some type II alveolar epithelial cells (Fig. 1, E, I, and M). Some alveolar macrophages were slightly positive for MMP-2, MT1-MMP, and TIMP-2. Staining for p53 and that for $\mathrm{Ki}-67$ were negligible (Fig. 2, A and E).

Three Days after Bleomycin. Bronchiolar ciliated epithelial cells were replaced with cuboidal cells. Bronchiolar epithelial cells elongated to alveolar duct (alveolar bronchiolization) in terminal portions of bronchioles (Fig. 1D). Some of the type II alveolar epithelial cells around bronchioles were swollen. All these cell populations showed clear immunoreactivity for MMP-2, MT1-MMP, and TIMP-2 (Fig. 1, F, J, and N). Alveolar macrophages weakly reacted for MMP-2, MT1-MMP, and TIMP-2. Nuclear staining for p53 was observed mainly in cuboidal cells in terminal portions of bronchioles. Staining for Ki-67 occurred in the basal layer of terminal bronchioles (Fig. 2, B and F).

Seven Days after Bleomycin. A number of small tubular structures of bronchiolar epithelial cells were seen around the fibrosis in alveoli, indicating the progress of alveolar bronchiolization. Swollen and/or elongated epithelial cells were located in the peripheral region of fibrotic areas (Fig. 1C). Strong immunoreactions for MMP-2, MT1-MMP, and TIMP-2 were noted in swollen and/or elongated epithelial cells in the peripheral regions of fibrotic areas (Fig. 1, G, K, and O). Type II alveolar epithelial cells and alveolar macrophages showed clear immunoreactions for MMP-2, MT1-MMP, and TIMP-2 in this stage. Interstitial cells showed much weaker immunoreactivity to MMP-2, MT1-MMP, and TIMP-2 than did epithelial cell populations. Bronchiolar epithelial cells in alveoli showed a unique reaction pattern; they reacted to MT1-MMP and TIMP-2 more strongly than to MMP-2. Nuclear staining for p53 was seen predominantly in swollen and/or elongated alveolar epithelial cells in the peripheral region of fibrotic areas (Fig. 2C). Some bronchiolar epithelial cells showed slight nuclear staining for p53. Many bronchiolar epithelial cells in alveoli showed nuclear staining for Ki-67 (Fig. 2G).

Twenty-Eight Days after Bleomycin. There were bronchiolar epithelial cells in alveoli and hyperplastic type II alveolar epithelial cells around alveolar wall fibrosis (Fig. 1D). Type II alveolar epithelial cells showed clear reactions for MMP-2 and MT1-MMP (Fig. 1, H, L, and P). Some alveolar macrophages showed weak immunoreactivity to MMP-2, MT1MMP, and TIMP-2. The reaction for TIMP-2 in those cells was stronger than those for MMP-2 and MT1MMP. Some type II alveolar epithelial cells showed nuclear stainings for p53 and Ki-67 (Fig. 2, D and H).

\section{In Situ Hybridization for MT1-MMP}

To identify which types of cells express MT1-MMP, we performed in situ hybridization. Using the antisense probe for MT1-MMP mRNA, hybridization signals were detected intensely in elongated alveolar epithelial cells (Fig. 3A). These cells showed positive staining for surfactant protein on serial sections (Fig. 3B). The sense probe gave rise to no signal (Fig. 3C).

\section{Detection of Gelatinolytic Activity}

Gelatin zymography revealed gelatinolytic bands, corresponding to the latent $(68 \mathrm{kDa})$ and activated forms (62 kDa) of MMP-2 in both bleomycin-treated and control rabbits. Bleomycin-treated rabbits exhibited an increased intensity of the activated form, compared with the latent form (Fig. 4A). Total gelatinolytic activity of MMP-2 was increased significantly at 3, 7, and 14 days after bleomycin administration (Fig. 4B). The ratio of activated MMP-2 to total MMP-2 was significantly greater at $3,7,14$, and 28 days in bleomycin-treated rabbits than in controls (Fig. $4 \mathrm{C}$ ).

\section{Western Blot Analysis for MT1-MMP}

Western blot analysis, by using monoclonal anti-MT1MMP antibody, detected $65 \mathrm{kDa}$ protein corresponding to MT1-MMP. In bleomycin-treated rabbits, the MT1-MMP protein was more clearly detected in comparison with controls (Fig. 5). The level of MT1-MMP appeared to correlate with the ratio of activated MMP-2 to total MMP-2 (Figs. $4 \mathrm{C}$ and 5).

\section{In Situ Zymography}

Weak gelatinolytic activity was observed in control rabbits (data not shown). At 3 days after bleomycin administration, we observed areas of intense gelatin degradation (Fig. 6A), where alveolar walls including type II alveolar epithelial cells were seen by Nomarski optics (Fig. 6D). At 28 days, some type II alveolar epithelial cells degraded gelatin film (Fig. 6, B and E). These activities were completely blocked at 3 days after bleomycin administration when sections were incubated with the metal chelator EDTA as an MMP inhibitor (Fig. 6C). When the sections were incubated at $4^{\circ} \mathrm{C}$, the gelatinolytic activity was not detected at 3 

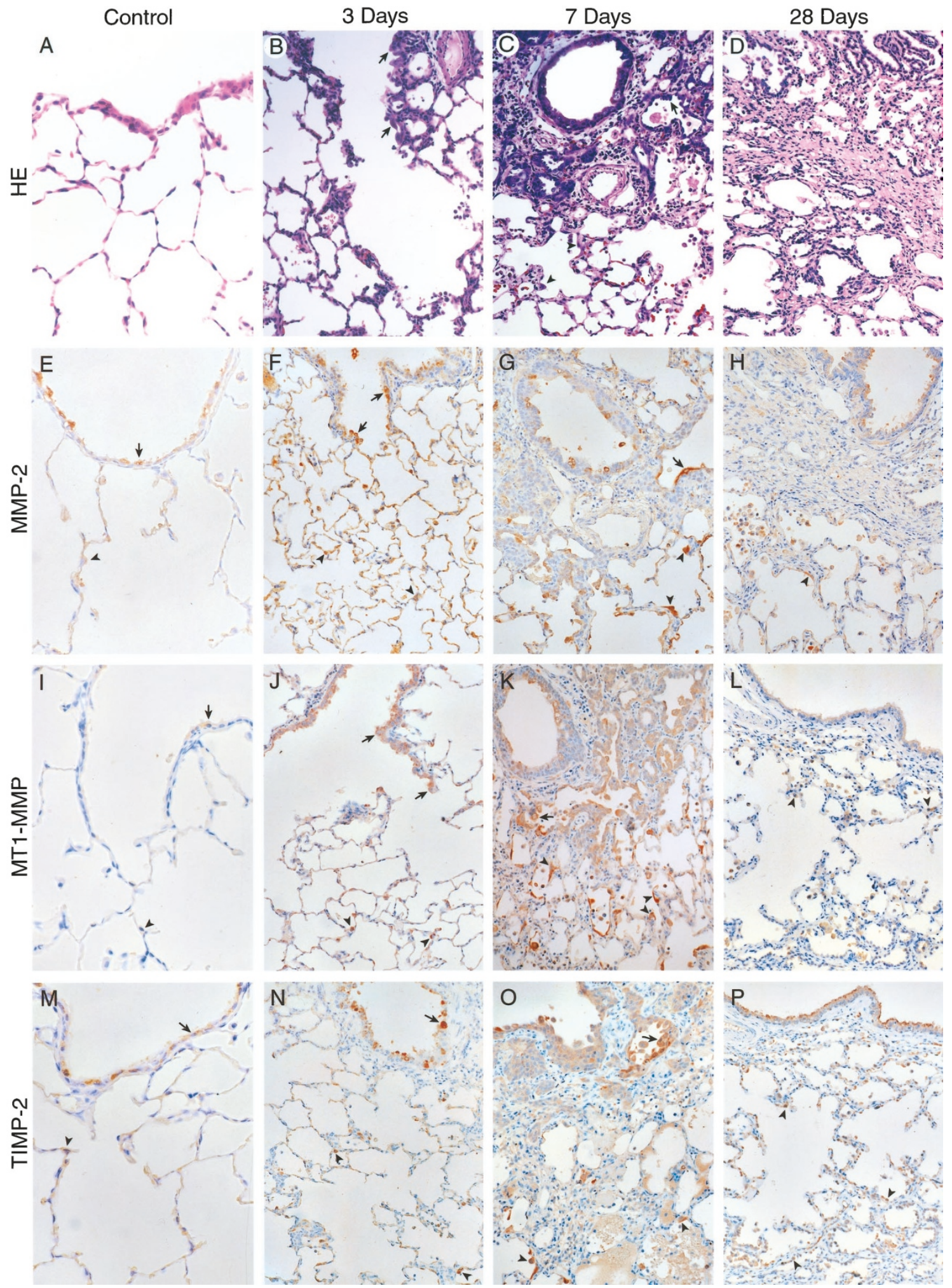

Figure 1.

Histological and immunohistological findings. A, Control lung tissues exhibited normally open alveoli with some macrophages in their air spaces. Matrix metalloproteinase (MMP)-2 (E), membrane type 1-matrix metalloproteinase (MT1-MMP) (I), and tissue inhibitor of metalloproteinase (TIMP)-2 (M) are slightly positive in some bronchiolar (arrows) and type II alveolar epithelial cells (arrowheads). Three days (B, F, J, and N), 7 days (C, G, K, and, 0), and 28 days (D, H, L, and P) after bleomycin instillation. B, Swollen cuboidal epithelial cells (arrows) in terminal bronchioles and type II alveolar epithelial cells (arrowheads) showed clear immunoreactivity for MMP-2 (F), MT1-MMP (J), and TIMP-2 (N). C, Bronchiolar epithelial cells in alveoli (arrows) and swollen and elongated alveolar epithelial cells (arrowheads) are seen around and within fibrosis. Strong immunoreactivity for MMP-2 (G), MT1-MMP (K), and TIMP-2 (0) is noted in swollen or elongated alveolar epithelial cells (arrowheads) and some of the bronchiolar epithelial cells in alveoli (arrows). D, Dense focal fibrosis and hyperplastic type II alveolar epithelial cells are found. Alveolar macrophages show slight immunoreactivity for MMP-2 (H), MT1-MMP (L), and TIMP-2 (P). The elongated alveolar epithelial cells (arrowheads) are immunostained for MMP-2 $(\mathrm{H})$, MT1-MMP $(\mathrm{L})$, and TIMP-2 $(\mathrm{P})$. Original magnification, $\times 50$. 

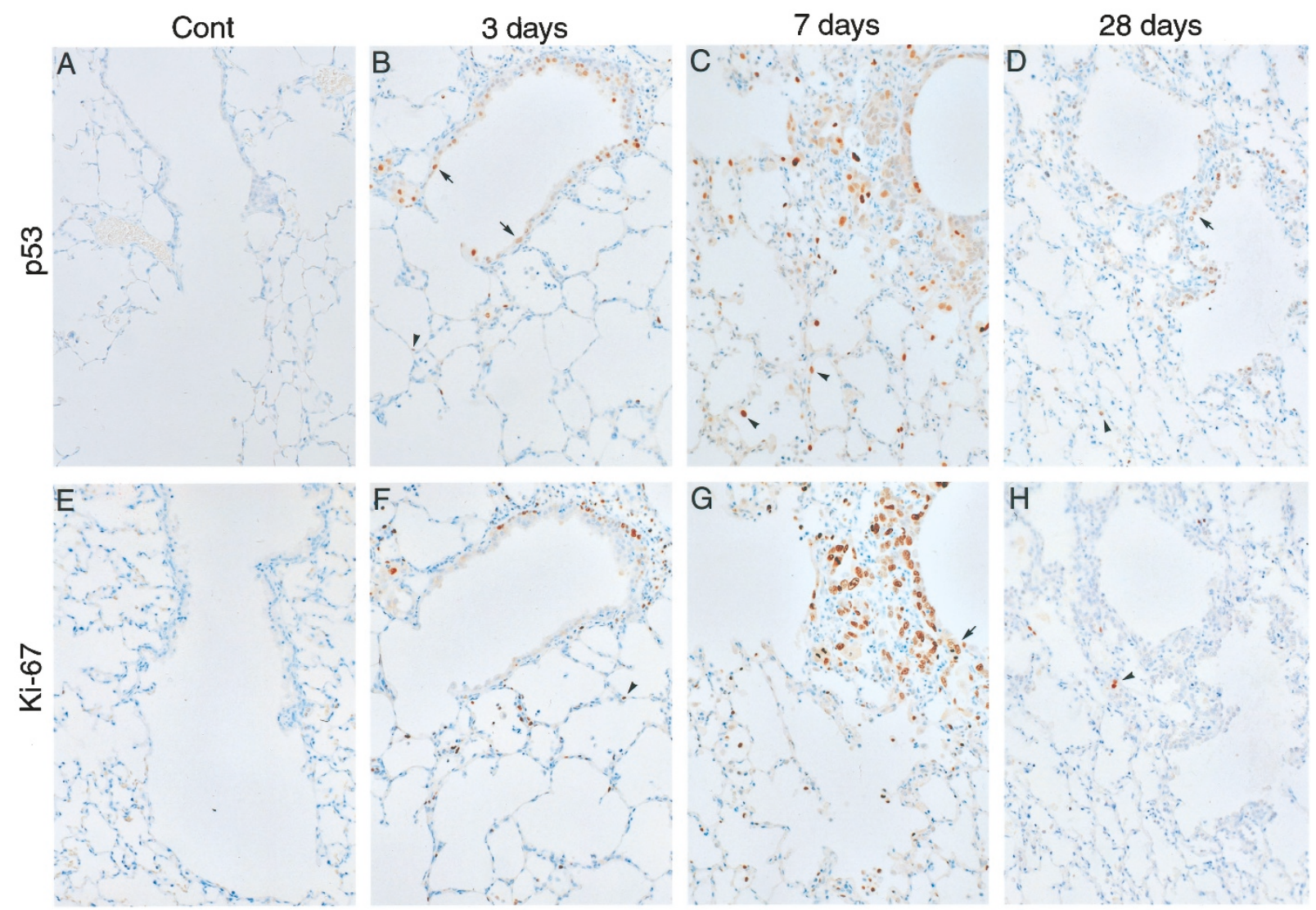

Figure 2.

Immunohistochemistry for p53 and Ki-67. A and E, No staining for p53 and Ki-67 is observed in control lungs. B and F, At 3 days, cuboidal bronchial (arrow) and some type II alveolar epithelial cells (arrowhead) show nuclear staining for p53. Basal cells of bronchioles and some type II alveolar epithelial cells (arrowhead) show nuclear staining for Ki-67. C and G, At 7 days, swollen or elongated alveolar epithelial cells show nuclear staining for p53 (arrowheads). In contrast, numerous Ki-67-positive cells were seen in bronchiolar epithelial cells in alveoli (arrow). D and H, At 28 days, hyperplastic type II alveolar epithelial cells show positive nuclear staining for p53 (arrowhead). Ki-67 is only occasionally positive in alveolar (arrowhead) and bronchiolar epithelial cells in alveoli. Original magnification, $\times 50$.

or 28 days. These results ensure that the observed gelatinolytic activity is attributable to the action of MMPs.

\section{Percentages of p53-Positive Cells and Ki-67 Labeling Index}

The percentages of p53 positive cells are shown in Fig. 7A. Nuclear staining for p53 in bronchial epithelial cells reached a peak at 1 day and then gradually decreased. Nuclear staining for p53 in alveolar epithelial cells reached a peak at 7 days. Bronchiolar epithelial cells in alveoli appeared at 3 days, and nuclear staining for p53 in these cells reached a peak at 14 days. In bronchial and alveolar epithelial cells, the peaks of p53 preceded those of Ki-67 labeling index (Figure 7, A and B). In contrast, the peak of Ki-67 labeling index in bronchiolar epithelial cells in alveoli preceded the peak of $\mathrm{p} 53$.

\section{Discussion}

\section{Increase of MMP-2 and p53}

We confirmed the increase of MMP-2 from the observation that total MMP-2 levels estimated by gelatin zymography increased significantly at 3,7 , and 14 days after bleomycin administration, compared with controls. In line with this, Bakowska and Adamson (1998) found that gelatinolytic activity is increased in bronchoalveolar lavage fluid of bleomycin-induced fibrosis. Swiderski et al (1998) showed that MMP-2 mRNA is also increased in homogenates of bleomycin-induced fibrotic lungs. In our immunohistochemical study, the reaction for MMP-2 was strongest in alveolar epithelial cells among cell populations. Indeed, type II alveolar epithelial cells are known to secret MMP-2 in vitro (d'Ortho et al, 1997; Pardo et al, 1997). Our results may indicate that the production of MMP-2 by alveolar epithelial cells increases while repairing alveoli.

In control rabbits, no p53 staining was observed, which is consistent with the findings that p53 protein is at low concentrations in the normal physiological condition and undetectable by immunohistochemistry (Levine, 1997). After bleomycin administration, we detected the immunoreaction for p53 in bronchiolar and alveolar epithelial cells. The proportion of p53positive cells was high in epithelial cells from 1 to 14 days as MMP-2 was increased. It is noteworthy that swollen and/or elongated alveolar epithelial cells, 

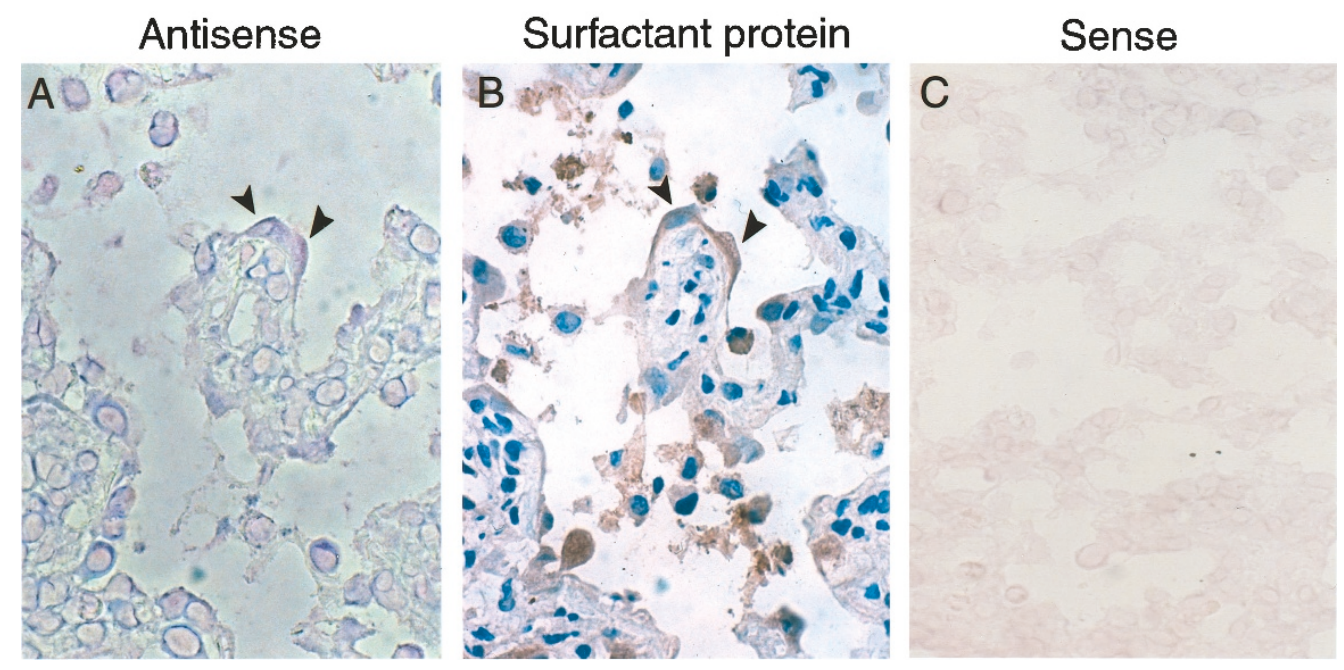

Figure 3.

In situ hybridization for MT1-MMP. A, Antisense MT1-MMP RNA probe shows the positive signals (dark purple) in swollen and/or elongated alveolar epithelial cells (arrowheads) at 7 days. B, These cells show positive staining for surfactant protein in serial sections (arrowheads). C, No specific signal is seen in sections hybridized with sense MT1-MMP RNA probe. Both tissues are slightly counterstained with nuclear fast red. Original magnification, $\times 150$.

which showed immunoreactivity for MMP-2, also showed nuclear staining for p53. Because p53 is known to be a nuclear factor that promotes the production of MMP-2 under the influence of p53 inducer (Bian and Sun, 1997), it is feasible that these changes in p53 activity in alveolar epithelial cells are responsible, at least in part, for the increased production of MMP-2 in bleomycin-induced lung fibrosis.

Several previous studies suggest that p53 is upregulated in response to DNA damage caused by bleomycin in the pathogenesis of pulmonary fibrosis (Kuwano et al, 2000; Mishra et al, 2000). p53 induces G1 or G2 arrest in the cell cycle and cell apoptosis following DNA damage, either to halt cell division until the damage is fully repaired or to eliminate the cells whose DNA is irreparably damaged (Kastan et al, 1995). The up-regulation of p53 following DNA damage may lead to delayed or impaired epithelialization, resulting in acute lung injury and progression to pulmonary fibrosis (Kuwano et al, 2000; Mishra et al, 2000).

To evaluate the effect of p53 on cell kinetics, we determined the fraction of cycling cells as measured by Ki-67 antigen expression in epithelial cells. In alveolar epithelial cells, the Ki-67 labeling index was lower after bleomycin administration, compared with that of bronchiolar epithelial cells, which is consistent with our previous finding (Kawamoto and Fukuda, 1990). Our results are in line with the possible arrest in cell cycle by a p53-dependent mechanism for alveolar epithelial cells. It is possible that the increased expression of p53 in alveolar epithelial cells results in cell cycle arrest as well as production of MMP-2. Overall, p53 may play important roles; it may, on the one hand, induce cell cycle arrest or apoptosis leading to impaired epithelialization and lung injury, and it may, on the other hand, promote the production of MMP-2 leading to the repair process of alveoli.

\section{Activation of MMP-2}

The ratio of activated MMP-2 to total MMP-2 estimated by gelatin zymography increased significantly at $3,7,14$, and 28 days after bleomycin treatment. An increased expression of MT1-MMP was observed by Western blot in the early stages following administration of bleomycin. MT1-MMP mRNA was detected predominantly in swollen and/or elongated epithelial cells with in situ hybridization. These cells showed positive staining for surfactant protein on serial sections, suggesting that the cells were type II alveolar epithelial cells or Clara cells (Kalina et al, 1992; Walker et al, 1986; Wohlford-Lenane and Synder, 1992). However, Clara cells were located in distal airway regions and alveolar bronchiolization after intratracheal bleomycin (Betsuyaku et al, 2000; Daly et al, 1998). Hence, the swollen and/or elongated epithelial cells were likely to be type II alveolar epithelial cells.

Alveolar epithelial cells showed gelatinolytic activity at 3 days and much less activity at 28 days. Pardo et al $(1996,1998)$ showed in a rat model of hyperoxic pulmonary damage that type II alveolar epithelial cells express MMP-2 mRNA and gelatinolytic activity with in situ zymography.

It has been suggested that the existing type II alveolar epithelial cells transform into type I cells in epithelial repair in pulmonary fibrosis (Aso et al, 1976; Evans et al, 1972). These previous findings and ours suggest that type II alveolar epithelial cells express MT1-MMP and MMP-2 and that activation of MMP-2 occurs on their cell surfaces in pulmonary fibrosis. We observed immunoreactivity for MMP-2 and MT1-MMP in swollen and/or elongated alveolar epithelial cells where activation of MMP-2 was likely. The observed morphological changes in epithelial cells and immunoreactions for MMP-2 and MT1-MMP may be relevant to the repair process of damaged alveoli. It is possible that the activation of MMP-2 leads to the 


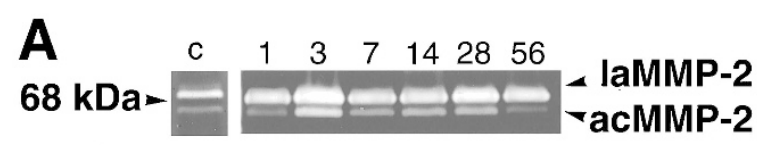

B

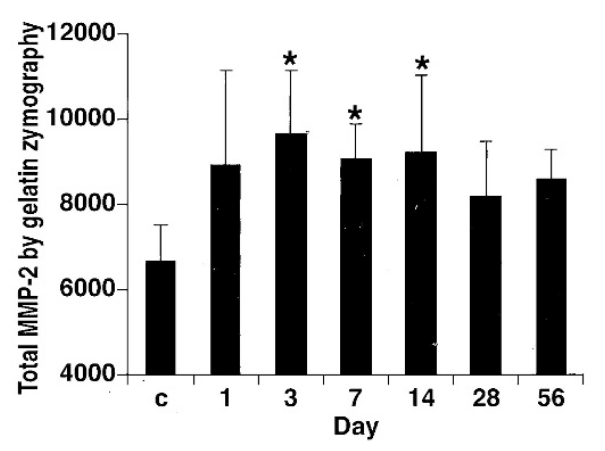

C

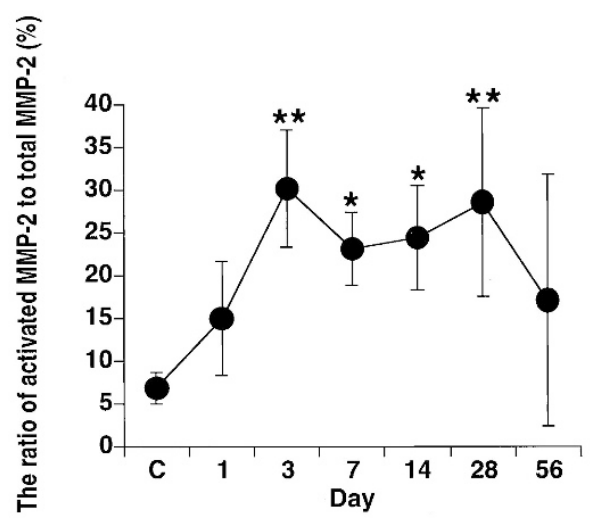

Figure 4.

Activation of MMP-2. A, One representative gelatin zymography of the samples shows the latent MMP-2 (68 kDa, la MMP-2) and the activated MMP-2 (62 $\mathrm{kDa}$, ac MMP-2). Bands for activated MMP-2 are stronger in the bleomycintreated rabbits than controls, particularly at 3 days through 28 days after bleomycin administration. B, Total MMP-2 estimated by gelatin zymography. Total gelatinolytic activity of MMP-2 is significantly higher than controls on 3 , 7 , and 14 days after bleomycin $\left({ }^{\star} p<0.05\right)$. C, Densitometric analysis shows that the ratios of activated MMP-2 to total MMP-2 on 3, 7, 14, and 28 days after bleomycin are significantly greater than that of controls $\left({ }^{*} p<0.05,{ }^{* *} p\right.$ $<0.01)$.

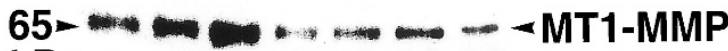 kDa C $\quad 1 \quad 3 \quad 7 \quad 142856$}

Figure 5.

One representative Western blot analysis of MT1-MMP. Expression of MT1MMP appeared to be increased after bleomycin instillation.

elongation of epithelial cells. In developing fetal lungs, MMP-2 and MT1-MMP of alveolar epithelial cells were found to be involved in elongation of epithelial cells and thinning of basement membrane (Arden et al, 1993; Fukuda et al, 2000). In cancer cell lines, MMP-2 and other proteases were shown to be involved in surface protrusions called "invadopodia" (Monsky et al, 1993). Localization of MT1-MMP to invadopodia was also confirmed by immunohistochemistry (Naka- hara et al, 1997). The MT1-MMP-mediated activation of MMP-2 in alveolar epithelial cells may, therefore, play a role, not only in the turnover and disruption of basement membrane, but also in the elongation and migration in the repair process of alveolar epithelial cells.

In summary, our results confirmed the increase and activation of MMP-2 in bleomycin-induced pulmonary fibrosis. The immunohistochemical study showed that the swollen and/or elongated type II alveolar epithelial cells reacted to MMP-2, MT1-MMP, and TIMP-2 more strongly than other cell populations. p53 was suggested to be relevant to the expression of MMP-2. Type II alveolar epithelial cells were suggested to express MT1-MMP and activate MMP-2, which may lead to the elongation and migration of alveolar epithelial cells in the repair process of bleomycin-induced pulmonary fibrosis.

\section{Materials and Methods}

\section{Animal Models}

The experimental procedures were approved by the Animal Experimental Ethical Review Committee of Nippon Medical School. Details of animal-model and intratracheal instillation of bleomycin were described previously (Yaguchi et al, 1998). Briefly, male Japanese rabbits weighing between 2.5 and $3.0 \mathrm{~kg}$ were anesthetized with $15 \mathrm{mg} / \mathrm{kg}$ of body weight of thiopental sodium intravenously, followed by an intratracheal injection of bleomycin hydrochloride $(10 \mathrm{mg} / \mathrm{kg}$ of body weight) (Nippon Kayaku Company, Tokyo, Japan). Control rabbits were administered $1.0 \mathrm{ml}$ of only sterile saline. Five bleomycin-treated rabbits and one control rabbit were killed on each of Days 1, 3, 7, 14,28 , and 56 after administration. Deep anesthesia was induced in each animal with thiopental sodium given intravenously ( $30 \mathrm{mg} / \mathrm{kg}$ of body weight) before opening the chest and abdomen by a midline incision. The lungs were removed en bloc immediately after killing by phlebotomizing the intra-abdominal great vessels.

For protein extraction, small portions of the lung tissue were immediately frozen at $-80^{\circ} \mathrm{C}$. The remainders of the lung were inflated at a pressure of 20 $\mathrm{cm} \mathrm{H}_{2} \mathrm{O}$ via trachea with a solution of $4 \%$ paraformaldehyde in $0.1 \mathrm{M}$ phosphate buffer, $\mathrm{pH} 7.4$. The trachea was ligated and then immersed in the 4\% paraformaldehyde at $4^{\circ} \mathrm{C}$ overnight. For light microscopy and immunohistochemistry, the lungs were cut into 3- to 4-mm-thick axial slices, and the specimens were dehydrated and embedded in paraffin. To perform in situ hybridization, the lungs were cut into small pieces, washed with $30 \%$ sucrose/PBS, and frozen into OCT compound (Miles, Elkhart, Indiana).

\section{Histology and Immunohistochemistry of MMP-2,} MT1-MMP, TIMP-2, p53, and Ki-67

Light microscopy was conducted on 3- $\mu$ m-thick paraffin sections stained with hematoxylin and eosin. Immunohistochemistry was done on 3- $\mu$ m-thick par- 

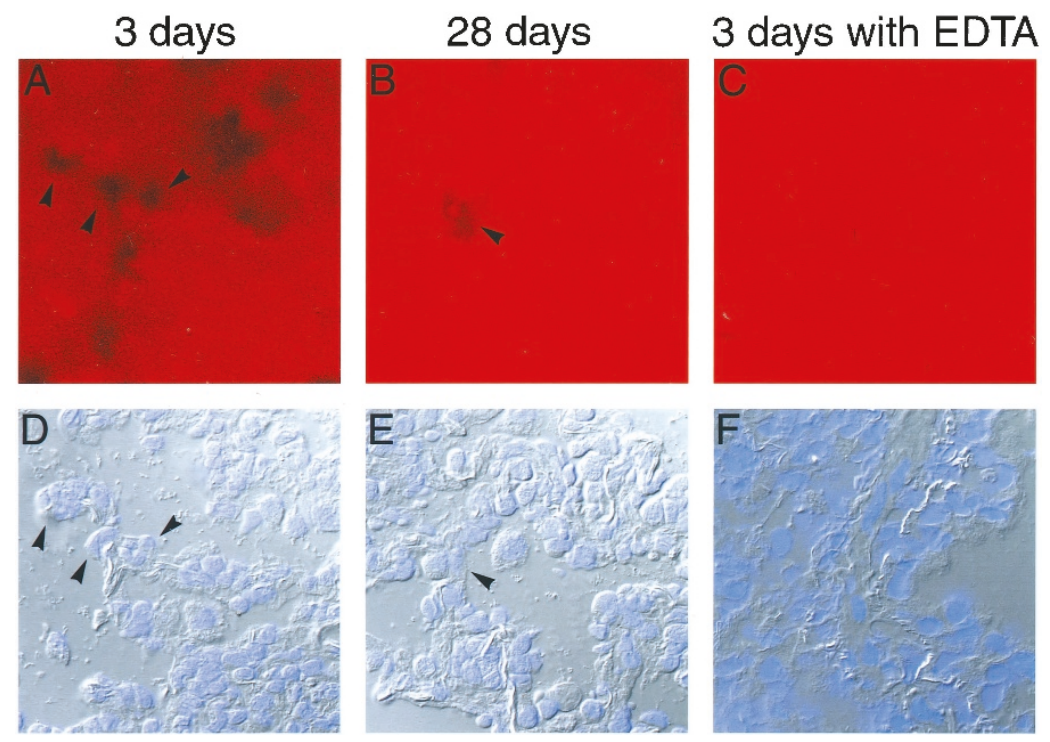

\section{Figure 6.}

Laser confocal micrographs of in situ zymography (A, B, and C). Identical tissue samples are observed by Nomarski optics with nuclear stain (D, E, and F). At 3 days, alveolar epithelial cells (arrowheads) show the gelatinolytic activity (A). At 28 days, gelatinolytic activity was markedly reduced (B). In the presence of EDTA, as an inhibitor of MMPs, no gelatinolytic activity is detected at 3 days ( $C$ and $F$ ).

affin sections treated with $0.3 \% \mathrm{H}_{2} \mathrm{O}_{2}$ in methanol for 30 minutes to block endogenous peroxidase activity. To unmask reactive sites, the sections for MMP-2, MT1-MMP, and TIMP-2 were incubated with $8 \mathrm{M}$ guanidine in $0.1 \mathrm{M}$ Tris- $\mathrm{HCl}, \mathrm{pH} 7.6$, overnight. The sections for $\mathrm{p} 53$ and $\mathrm{Ki}-67$ were microwaved for 10 minutes with $0.1 \mathrm{M}$ citrate buffer, $\mathrm{pH}$ 6.0. After these treatments, all sections were incubated with normal goat serum for 10 minutes. After light rinsing with PBS, the sections were treated with each primary antibody at $4^{\circ} \mathrm{C}$ overnight: anti-p53 mouse monoclonal antibody (Do-7; DAKO, Glostrup, Denmark), anti-Ki-67 mouse monoclonal antibody (MIB-5; Immunotech, Marseille, France), anti-MMP-2 mouse monoclonal antibody (clone 42-5D11), anti-MT1-MMP mouse monoclonal antibody (clone 114-1F2), or anti-TIMP-2 mouse monoclonal antibody (clone 67-4H11) (all antibodies from Fuji Chemical Industries, Takaoka, Japan). Then these sections were incubated with biotinylated goat anti-mouse IgG antibody and an avidinbiotin peroxidase complex (ABC) (DAKO). The color was developed with a solution of 3, 3'diaminobenzidine and $\mathrm{H}_{2} \mathrm{O}_{2}$ and counterstained with Mayer's hematoxylin. All the anti-MMP antibodies recognize both the latent and activated forms of their respective MMP (Fujimoto et al, 1993a, 1993b; Sato et al, 1994). The antibodies against MMP-2, MT1-MMP, TIMP-2, p53, and Ki-67 have been confirmed to crossreact with rabbit tissues by Western blotting (Fukuda et al, 2000; Joyce et al, 1996; Le Goas et al, 1997; Tatsuguchi et al, 1999).

\section{Anti-Rabbit Surfactant Antibody}

A polyclonal antibody to rabbit surfactant protein was raised in chickens previously (Yoneyama, 1988). This antibody reacted with the 29 - to $35-\mathrm{kDa}$ protein group that was presumed to be surfactant protein-A (King and MacBeth, 1979; Phelps and Taeusch, 1985).

\section{Preparation of Crude Cell Membrane Fraction and Western Blot Analysis for MT1-MMP}

A portion of the frozen lung tissue sample was homogenized in lysis buffer (25 mM Tris- $\mathrm{HCl}, \mathrm{pH} 7.5,8.5 \%$ sucrose, $150 \mathrm{~mm} \mathrm{NaCl}, 10 \mathrm{~mm} \mathrm{CaCl}_{2}$ including $10 \mu \mathrm{g} / \mathrm{ml}$ aprotinin, $10 \mu \mathrm{g} / \mathrm{ml}$ pepstatin A, $10 \mu \mathrm{g} / \mathrm{ml}$ leupeptin, and $1 \mathrm{~mm}$ phenylmethylsulphonyl fluoride as protease inhibitors). After centrifugation at 15,000 rpm for 50 minutes, supernatant containing crude cell membrane fraction was collected and used for Western blotting (Okada et al, 1997). Proteins were separated by electrophoresis on $10 \%$ polyacrylamide gels under reducing conditions. The proteins were then electrophoretically transferred to polyvinylidene difluoride (PVDF) membrane (Hybond-P; Amersham Pharmacia Biotech, Uppsala, Sweden). After treatment with blocking solution, the PVDF membrane was incubated at $4^{\circ} \mathrm{C}$ overnight with anti-MT1-MMP monoclonal antibody diluted 1:2000 in TNT buffer (25 $\mathrm{mm}$ Tris- $\mathrm{HCl}, 150 \mathrm{~mm} \mathrm{NaCl}, 0.01 \%$ Tween 20, pH 8.0) containing 5\% BSA. The PVDF membrane was washed and incubated with peroxidase-conjugated goat antimouse IgG antibody (Amersham). After washing in TNT buffer, peroxidase activity was detected with an enhanced chemiluminescence kit (Amersham). The protein concentrations were measured by Bio-Rad DC protein assay kits (Bio-Rad, Hercules, California), using BSA as standard.

\section{In Situ Hybridization for MT1-MMP}

Human MT1-MMP cDNA (kindly provided by Dr. H. Sato, Cancer Research Institute, Kanazawa, Japan) was subcloned into pGEM4 vector (Promega, Madi- 
A

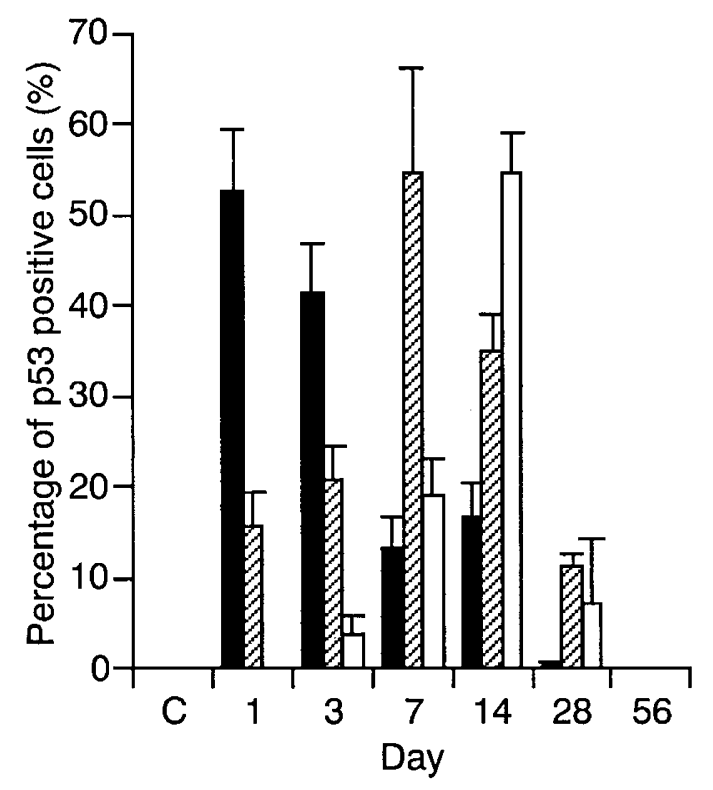

B

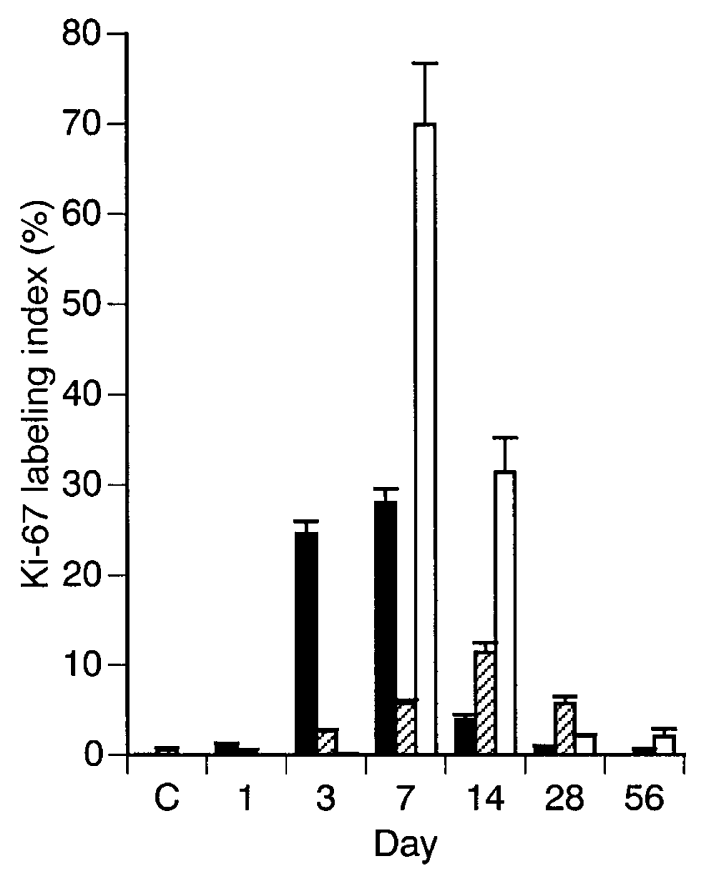

Figure 7.

Ki-67 labeling index and percentages of p53-positive cells. A, p53 nuclear staining in bronchial epithelial cells, alveolar epithelial cells, and bronchiolar epithelial cells in alveoli reaches a peak at 1, 7, and 14 days, respectively. B, Ki-67 labeling index. Note dramatic increase and cessation in labeled bronchiolar epithelial cells in alveoli between 7 and 28 days after bleomycin administration. There are few type II alveolar epithelial cells labeled with Ki-67.

son, Wisconsin). The plasmid was linearized by digestion with restriction enzymes (HindIII and EcoRI) and used as a template for synthesizing a single strand RNA probe. The RNA probes, transcribed with T7 RNA polymerase and SP6 RNA polymerase, were labeled with digoxigenin-11-UTP according to the instructions of the manufacturer (Roche Molecular Biochemicals, Mannheim, Germany). Frozen sections (5- $\mu \mathrm{m}$ thick) were treated with $20 \mu \mathrm{g} / \mathrm{ml}$ proteinase $\mathrm{K}$ (Sigma Chemical, St. Louis, Missouri) for 10 minutes at $37^{\circ} \mathrm{C}$. After acetylation with $0.25 \%$ acetic anhydrite, the sections were hybridized with antisense RNA (T7) or sense RNA probes (SP6) at $48^{\circ} \mathrm{C}$ overnight. Both digoxigenin-labeled cRNA probes were applied at 500 $\mathrm{ng} / \mathrm{ml}$. The sections were washed under high-stringency conditions to reduce the background and incubated with alkaline phosphate-labeled antidigoxigenin antibody (Roche Molecular Biochemicals). The color was developed by 5-nitoroblue tetrazolium chloride as recommended by the manufacturer. The sections were lightly counterstained with nuclear fast red. To identify alveolar epithelial cells, surfactant protein was stained on serial lung sections, using the ABC method.

\section{Gelatin Zymography}

Ten micrograms of total protein from lung homogenate supernatants of each animal was applied to gelatin zymography, as described previously (Yaguchi et al, 1998). Briefly, electrophoresis was carried out on $10 \%$ polyacrylamide gels containing $0.1 \%$ gelatin under nonreducing conditions. After electrophoresis, the gels were washed in $2.5 \%$ Triton X-100 to remove sodium dodecyl sulfate, incubated for 16 hours at $37^{\circ} \mathrm{C}$, and stained with $0.1 \%$ Coomassie Brilliant Blue R250 (Sigma Chemical). Densitometric analysis of the gels was performed using NIH image software (Image, v. 1.62; National Institutes of Health, Bethesda, Maryland) and a high-resolution scanner (Kleiner and Stetler-Stevenson, 1994). The ratio of activated MMP-2 to total MMP-2 was estimated from their gelatinolytic activities.

\section{Detection of Gelatinolytic Activity by In Situ Zymography}

Immunohistochemical study cannot distinguish between the latent and activated MMPs. Activity of MMPs is influenced by TIMPs in situ. Therefore, to demonstrate the expression of gelatinolytic activity in frozen sections of bleomycin-induced pulmonary fibrosis, we applied in situ zymography. We used the methods of d'Ortho et al (1998). Texas red sulphonyl chloride (Molecular Probes, Eugene, Oregon) was conjugated with gelatin according to the instructions of the manufacturer. Silan-coating glass slides were coated with conjugated gelatin-Texas red for 2 hours at room temperature (gelatin-TR films). This was removed and the coating fixed with $4 \%$ paraformaldehyde. After repeated washing in PBS, glass slides were dried at $37^{\circ} \mathrm{C}$. The frozen lungs were sectioned (4 to $6 \mu \mathrm{m}$ ) in a cryostat at $-30^{\circ} \mathrm{C}$ and then taken onto gelatin-TR coated glass slides. Slides were covered 
with incubation buffer and incubated in humidified chambers at $37^{\circ} \mathrm{C}$ for 32 hours. After fixation, slides were mounted in VectorShield with 4', 6-diamidino-2phenylindole (DAPI; Vector Laboratories. Burlingame, California) and viewed on a confocal laser scanning microscope (CLSM, TCS-SP; Leica Lasertechnik, Heidelberg, Germany). To identify the nuclei, an argon ion UV laser for the detection of blue DAPI was used. A krypton/argon laser, emitting at $568 \mathrm{~nm}$, was used to detect red gelatin-TR films. Fluorescence images were collected by scanning gelatin-TR films (Texas red) and the nuclei (DAPI) separately. Observation on identical fields was performed using Nomarski optics. Images were processed using Adobe Photoshop software, version 5.0 (Adobe Systems, Mountain View, California). Parallel incubations at $4^{\circ} \mathrm{C}$ were performed to confirm enzymatic activity. Sections treated with 20 mM EDTA were used as negative controls.

\section{Percentages of p53-Positive Cells}

More than 1000 cell nuclei of the bronchiolar epithelial cells in bronchioles, alveolar epithelial cells, and bronchiolar epithelial cells in alveoli were counted by microscopy at $\times 600$ from the terminal bronchiole to alveolar regions. Percentages of cells positive for p53 were determined.

\section{Statistical Analysis}

Data are presented as mean \pm SD. Statistical differences between groups were determined by one-way ANOVA with Dunnet's multiple comparison test. A probability of $p<0.05$ (two-tailed) was considered to be significant.

\section{Acknowledgements}

The authors wish to thank Dr. Hiroshi Sato (Department of Molecular Virology and Oncology, Cancer Research Institute, Kanazawa University) for providing CDNA of MT1-MMP and Dr. Shoji Kudoh (Fourth Department of Internal Medicine, Nippon Medical School) for his encouragement. The authors are also grateful to Dr. Takamoto Yaguchi (Department of Respiratory Medicine, School of Medicine, Juntendo University), Ms. Kyoko Wakamatsu and Ms. Arimi Ishikawa (Department of Pathology, Nippon Medical School) for their technical assistance.

\section{References}

Arden MG, Spearman MA, and Adamson IYR (1993). Degradation of type IV collagen during the development of fetal rat lung. Am J Respir Cell Mol Biol 9:99-105.

Aso Y, Yoneda K, and Kikkawa Y (1976). Morphologic and biochemical study of pulmonary changes induced by bleomycin in mice. Lab Invest 35:558-568.

Bakowska J and Adamson IYR (1998). Collagenase and gelatinase activities in bronchoalveolar lavage fluids during bleomycin-induced lung injury. J Pathol 185:319-323.
Betsuyaku T, Fukuda Y, Parks WC, Shipley JM, and Senior RM (2000). Gelatinase B is required for alveolar bronchiolization after intratracheal bleomycin. Am J Pathol 157:525-535.

Bian J and Sun Y (1997). Transcriptional activation by p53 of the human type IV collagenase (gelatinase A or matrix metalloproteinase 2) promoter. Mol Cell Biol 17:6330-6338.

Daly HE, Beacher-Allan CM, Paxhia AT, Ryan RM, Barth RK, and Finkelstein JN (1998). Cell-specific gene expression reveals changes in epithelial cell populations after bleomycin treatment. Lab Invest 78:393-400.

d'Ortho MP, Clerici C, Yao PM, Delacourt C, Delclaux C, Franco-Montoya ML, Harf A, and Lafuma C (1997). Alveolar epithelial cells in vitro produce gelatinases and tissue inhibitor of matrix metalloproteinase-2. Am J Physiol Lung Cell Mol Physiol 273:L663-L675.

d'Ortho MP, Stanton H, Butler M, Atkinson SJ, Murphy G, and Hembry RM (1998). MT1-MMP on the cell surface causes focal degradation of gelatin films. FEBS Lett 421 : 159-164.

Evans MJ, Stephens RJ, Cabral LJ, and Freeman G (1972). Cell renewal in the lungs of rats exposed to low levels of NO2. Arch Environ Health 24:180-188.

Fujimoto N, Mouri N, Iwata K, Ohuchi E, Okada Y, and Hayakawa T (1993a). A one-step sandwich enzyme immunoassay for human matrix metalloproteinase 2 (72-kDa gelatinase/type IV collagenase) using monoclonal antibodies. Clin Chim Acta 221:91-103.

Fujimoto N., Zhang J, Iwata K, Shinya T, Okada $\mathrm{Y}$, and Hayakawa T (1993b). A one-step sandwich enzyme immunoassay for tissue inhibitor of metalloproteinases-2 using monoclonal antibodies. Clin Chim Acta 220:31-45.

Fukuda Y, Ishizaki M, Kudoh S, Kitaichi M, and Yamanaka N (1998). Localization of matrix metalloproteinases-1, -2, and -9 and tissue inhibitor of metalloproteinase-2 in interstitial lung diseases. Lab Invest 78:687-698.

Fukuda Y, Ishizaki M, Okada Y, Seiki M, and Yamanaka N (2000). Matrix metalloproteinases and tissue inhibitor of metalloproteinase-2 in fetal rabbit lung. Am J Physiol Lung Cell Mol Physiol 279:L555-L561.

Hayashi T, Stetler-Stevenson WG, Fleming MV, Fishback N, Koss MN, Liotta LA, Ferrans VJ, and Travis WD (1996). Immunohistochemical study of metalloproteinases and their tissue inhibitors in the lungs of patients with diffuse alveolar damage and idiopathic pulmonary fibrosis. Am $\mathrm{J}$ Pathol 149:1241-1256.

Joyce NC, Navon SE, Roy S, and Zieske JD (1996). Expression of cell cycle-associated proteins in human and rabbit corneal endothelium in situ. Invest Ophthalmol Vis Sci 37: 1566-1575.

Kalina M, Mason RJ, and Shannon JM (1992). Surfactant protein $\mathrm{C}$ is expressed in alveolar type II cells but not in Clara cells of rat lung. Am J Respir Cell Mol Biol 6:594-600.

Kastan MB, Canman CE, and Leonard CJ (1995). P53, cell cycle control and apoptosis: Implications for cancer. Cancer Metastasis Rev 14:3-15.

Kastan MB, Onyekwere O, Sidransky D, Vogelstein B, and Craig RW (1991). Participation of p53 protein in the cellular response to DNA damage. Cancer Res 51:6304-6311. 
Kawamoto $M$ and Fukuda $Y$ (1990). Cell proliferation during the process of bleomycin-induced pulmonary fibrosis in rats. Acta Pathol Jpn 40:227-238.

King RJ and MacBeth MC (1979). Physicochemical properties of dipalmitoyl phosphatidylcholine after interaction with an apolipoprotein of pulmonary surfactant. Biochem Biophys Acta 557:86-101.

Kleiner DE and Stetler-Stevenson WG (1994). Quantitative zymography: Detection of picogram quantities of gelatinases. Anal Biochem 218:325-329.

Kuwano K, Hagimoto N, Tanaka T, Kawasaki M, Kunitake R, Miyazaki H, Kaneko Y, Matsuba T, Maeyama T, and Hara N (2000). Expression of apoptosis-regulatory genes in epithelial cells in pulmonary fibrosis in mice. J Pathol (190):221-229.

Kuwano K, Kunitake R, Kawasaki M, Nomoto Y, Hagimoto N, Nakanishi Y, and Hara N (1996). P21Waf1/Cip1/Sdi1 and p53 expression in association with DNA strand breaks in idiopathic pulmonary fibrosis. Am J Respir Crit Care Med 154: 477-483.

Le Goas F, May P, Ronco P, and Caron de Fromentel C (1997). cDNA cloning and immunological characterization of rabbit p53. Gene 185:169-173.

Levine AJ (1997). p53, the cellular gatekeeper for growth and division. Cell 88:323-331.

Mishra A, Doyle NA, and Martin WJ II (2000). Bleomycinmediated pulmonary toxicity: Evidence for a p53-mediated response. Am J Respir Cell Mol Biol 22:543-549.

Monsky WL, Kelly T, Lin CY, Yeh Y, Stetler-Stevenson WG, Mueller SC, and Chen WT (1993). Binding and localization of $M(r)$ 72,000 matrix metalloproteinase at cell surface invadopodia. Cancer Res 53:3159-3164.

Nakahara H, Howard L., Thompson EW, Sato H, Seiki M, Yeh Y, and Chen WT (1997). Transmembrane/cytoplasmic domain-mediated membrane type 1-matrix metalloprotease docking to invadopodia is required for cell invasion. Proc Natl Acad Sci USA 94:7959-7964.

Nelson WG and Kastan MB (1994). DNA strand breaks: The DNA template alterations that trigger p53-dependent DNA damage response pathways. Mol Cell Biol 14:1815-1823.

O'Connor CM and FitzGerald MX (1994). Matrix metalloproteases and lung disease. Thorax 49:602-609.

Okada A, Tomasetto C, Lutz Y, Bellocq JP, Rio MC, and Basset P (1997). Expression of matrix metalloproteinases during rat skin wound healing: Evidence that membrane type-1 matrix metalloproteinase is a stromal activator of pro-gelatinase A. J Cell Biol 137:67-77.

Okudela K, Ito T, Mitsui H, Hayashi H, Udaka N, Kanisawa M, and Kitamura $\mathrm{H}$ (1999). The role of p53 in bleomycin-induced DNA damage in the lung. A comparative study with the small intestine. Am J Pathol 155:1341-1351.

Pardo A, Barrios R, Maldonado V, Melendez J, Perez J, Ruiz V, Segura-Valdez L, Sznajder JI, and Selman M (1998). Gelatinases $A$ and $B$ are up-regulated in rat lungs by subacute hyperoxia: Pathogenetic implications. Am J Pathol 153:833-844.
Pardo A, Ridge K, Uhal B, Sznajder JI, and Selman M (1997). Lung alveolar epithelial cells synthesize interstitial collagenase and gelatinases $A$ and $B$ in vitro. Int $J$ Biochem Cell Biol 29:901-910.

Pardo A, Selman M, Ridge K, Barrios R, and Sznajder Jl (1996). Increased expression of gelatinases and collagenase in rat lungs exposed to $100 \%$ oxygen. Am J Respir Crit Care Med 154:1067-1075.

Phelps DS and Taeusch WH Jr (1985). A comparison of the major surfactant-associated proteins in different species. Comp Biochem Physiol B 82:441-446.

Sato H, Takino T, Okada Y, Cao J, Shinagawa A, Yamamoto E, and Seiki M (1994). A matrix metalloproteinase expressed on the surface of invasive tumour cells. Nature 370:61-65.

Seiki M (1999). Membrane-type matrix metalloproteinases. APMIS 107:137-143.

Swiderski RE, Dencoff JE, Floerchinger CS, Shapiro SD, and Hunninghake GW (1998). Differential expression of extracellular matrix remodeling genes in a murine model of bleomycin-induced pulmonary fibrosis. Am J Pathol 152: 821-828.

Tatsuguchi A, Fukuda Y, Ishizaki M, and Yamanaka N (1999). Localization of matrix metalloproteinases and tissue inhibitor of metalloproteinases-2 in normal human and rabbit stomachs. Digestion 60:246-254.

Velasco G, Cal S, Merlos-Suarez A, Ferrando AA, Alvarez S, Nakano A, Arribas J, and Lopez-Otin C (2000). Human MT6-matrix metalloproteinase: Identification, progelatinase A activation, and expression in brain tumors. Cancer Res 60:877-882.

Walker SR, Williams MC, and Benson B (1986). Immunocytochemical localization of the major surfactant apoproteins in type II cells, Clara cells, and alveolar macrophages of rat lung. J Histochem Cytochem 34:1137-1148.

Woessner JF Jr (1991). Matrix metalloproteinases and their inhibitors in connective tissue remodeling. FASEB J 5:21452154.

Wohlford-Lenane CL and Synder JM (1992). Localization of surfactant-associated proteins SP-A and SP-B mRNA in rabbit fetal lung tissue by in situ hybridization. Am J Respir Cell Mol Biol 7:335-343.

Yaguchi T, Fukuda Y, Ishizaki M, and Yamanaka N (1998). Immunohistochemical and gelatin zymography studies for matrix metalloproteinases in bleomycin-induced pulmonary fibrosis. Pathol Int 48:954-963.

Yoneyama K (1988). Immunohistochemical localization of pulmonary surfactants in fetal rabbit lung. Nippon Sanka Fujinka Gakkai Zasshi 40:1740-1746. 